\section{Trauma Surgery} \& Acute Care Open

\title{
Case of intracranial penetration of a metallic pipe through the orbit
}

\author{
Laila Malani Mohammad, Andrew P Carlson, Seymur Gahramanov, Jeremy Lewis
}

Department of Neurosurgery, University of New Mexico Hospital, Albuquerque, New Mexico, USA

\section{Correspondence to}

Dr Laila Malani Mohammad; LMoham@salud.unm. edue000040

Received 15 August 2016 Revised 4 September 2016 Accepted 6 September 2016
In March 2016, an 18-year-old left-handed male presented to our emergency department with a metal pipe penetrating intracranially through his right orbit (figure 1). The patient had been making an improvised firearm at home, when it backfired and dislodged the cylindrical barrel into his right eye socket. The patient was localizing only with the right upper extremity on arrival but did not follow commands. A CT scan demonstrated that $13.3 \mathrm{~cm}$ of the $23 \mathrm{~cm}$ metallic pipe extended through his right orbit though his anterior cranial fossa, into the middle cranial fossa (figure 2).
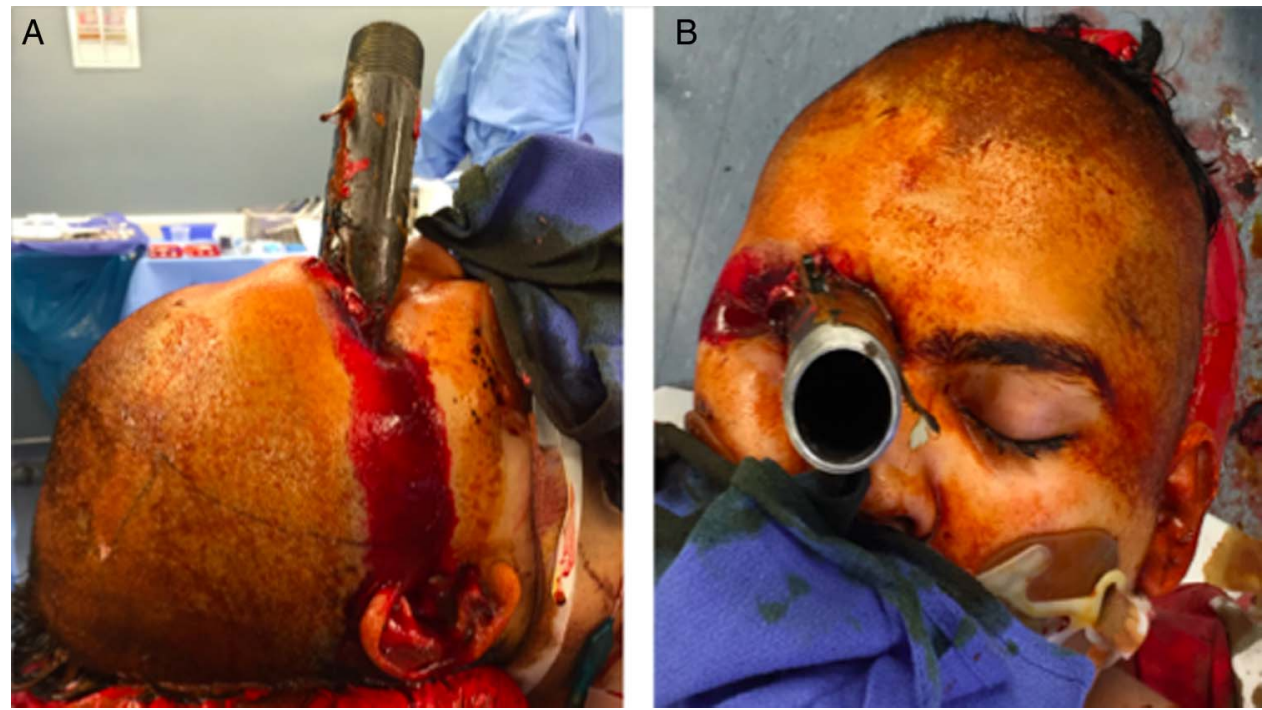

Figure 1 Intraoperative demonstration of metallic pipe penetrating the right orbit. Permission to publish patient's imaging was obtained.
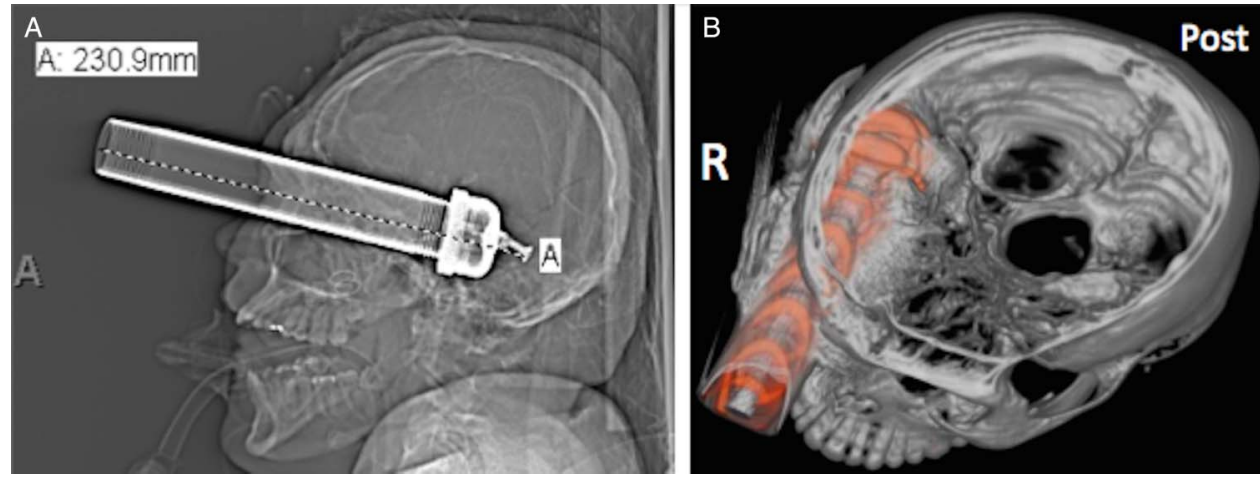

Figure 2 (A) Skull X-ray demonstrating a $23 \mathrm{~cm}$ metallic pipe. (B) Three-dimensional view rendering with the removal of the top of the skull demonstrates penetration of the right orbit into the middle cranial fossa.
WHAT WOULD YOU DO?

A. Removal of metal pipe followed by decompressive craniectomy.

B. Decompressive craniectomy followed by removal of the metal pipe.

C. Removal of metal pipe followed by orbital exenteration.

D. Removal of metal pipe followed by head CT scan for making decision regarding decompressive craniectomy.

E. Removal of pipe with local exploration via entry wound.
To cite: Mohammad LM, Carlson AP, Gahramanov S, et al. Trauma Surg Acute Care Open Published Online First: [please include Day Month Year] doi:10.1136/ tsaco-2016-000040 


\section{WHAT WE DID AND WHY Correct answer B}

We initially performed a decompressive craniectomy. A laterally based vascularized periosteal and temporalis muscle flap was created for use during closure for reconstruction of the skull base. After a large bone flap was elevated, dural defects from the trauma were appreciated. Following the dural opening, contused hemorrhagic temporal lobe was found to be budging out under high pressure. Therefore, a partial temporal lobectomy was performed, which allowed access to the tip of the metal pipe intracranially, with exposure of the frontal and temporal lobes, as well as anterior and middle fossa floors (figure 3). Next, the $2-3 \mathrm{~cm}$ diameter and $23 \mathrm{~cm}$ length pipe was carefully removed under direct visualization. Immediately on removal, the middle meningeal artery, ophthalmic artery, and cortical vessels began profusely bleeding. The bleeding was controlled with bipolar coagulation for arterial bleeding and other hemostatic agents for contused brain. There was also bony hemorrhage along the course of the pipe, which was controlled with bone wax. Had the metallic pipe been removed prior to obtaining intracranial access, the patient would have been at risk for uncontrollable active intracranial hemorrhage. Wide bony decompression allowed for complete exposure of the pipe and decompression of the brain. Multiple bone fragments were also removed from the brain tissue. The patient's globe and other orbital contents, including his eyelid, were found inside of the temporal lobe and were removed. The right optic nerve was found to be amputated by the trauma. For reconstruction, the vascularized temporalis muscle was reflected in the orbit to allow for separation of the intracranial and intraorbital compartments. Next, the frontal sinus mucosa was removed and a periosteal graft was reflected towards the anterior skull base. This allowed for coverage of the frontal sinus and a separation from the intracranial space. The orbit itself was packed and allowed to granulate in for delayed repair.
The patient began to follow commands 4 days following surgery. No cerebrospinal fluid (CSF) leak was observed. This case demonstrates the importance of the removal of penetrating intracranial foreign bodies under direct visualization for hemostasis and the need for a planned strategy for skull base repair. The general principles for the removal of intracranial foreign bodies revolve around the understanding of the surrounding vascular structures in order to respond to bleeding. The approach should be tailored to address the potential sources of hemorrhage that can turn rapidly fatal if the foreign body is tamponading a vessel laceration. The literature strongly supports surgical exploration over the blind removal of foreign objects. This is occasionally combined with planned endovascular control when a foreign body is adjacent to deep vascular structures, with difficult proximal control. In contaminated penetrating wounds, it is preferable to have vascularized tissue in order to repair skull base defects. Free grafts, such as fascia lata, do not provide as robust control of CSF leaks and can become a source of infection. This case demonstrated that even relatively large skull base wounds can be closed with well-planned local vascularized flaps from pericranium, temporoparietal fascia and temporalis muscle.

Contributors LMM, APC and SG were involved in writing and critical revision. $J \mathrm{~L}$ was involved in critical revision.

Competing interests None declared.

\section{Patient consent Obtained.}

Provenance and peer review Not commissioned; externally peer reviewed.

Open Access This is an Open Access article distributed in accordance with the Creative Commons Attribution Non Commercial (CC BY-NC 4.0) license, which permits others to distribute, remix, adapt, build upon this work non-commercially, and license their derivative works on different terms, provided the original work is properly cited and the use is non-commercial. See: http://creativecommons.org/ licenses/by-nc/4.0/
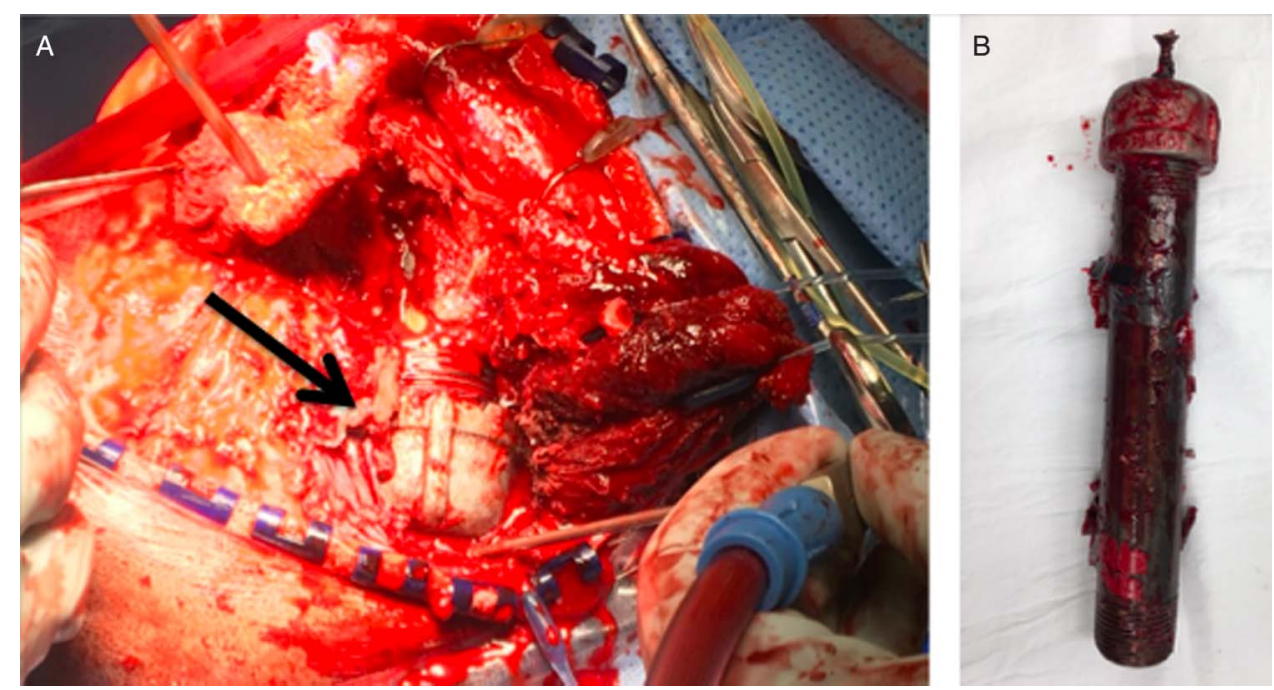

Figure 3 (A) Intraoperative imaging demonstrating the metallic pipe intracranially (black arrow) lateral to the temporal lobe. (B) Foreign body. 